\title{
SIMEU position paper on non-invasive respiratory support in COVID-19 pneumonia
}

\author{
Roberto Cosentini ${ }^{1}$ (1) Paolo Groff ${ }^{2}$ - Anna Maria Brambilla ${ }^{3} \cdot$ Renzo Camajori Todeschini ${ }^{4} \cdot$ Gianfilippo Gangitano $^{5}$. \\ Stella Ingrassia ${ }^{3} \cdot$ Roberta Marino $^{6} \cdot$ Francesca Nori $^{7} \cdot$ Fiammetta Pagnozzi $^{8} \cdot$ Francesco Panero $^{9} \cdot$ Rodolfo Ferrari $^{7}$ on \\ behalf of SIMEU NIV Group collaborators
}

Received: 12 April 2021 / Accepted: 6 December 2021 / Published online: 1 February 2022

(c) The Author(s), under exclusive licence to Società Italiana di Medicina Interna (SIMI) 2022

\begin{abstract}
The rapid worldwide spread of the Coronavirus disease (COVID-19) crisis has put health systems under pressure to a level never experienced before, putting intensive care units in a position to fail to meet an exponentially growing demand. The main clinical feature of the disease is a progressive arterial hypoxemia which rapidly leads to ARDS which makes the use of intensive care and mechanical ventilation almost inevitable. The difficulty of health systems to guarantee a corresponding supply of resources in intensive care, together with the uncertain results reported in the literature with respect to patients who undergo early conventional ventilation, make the search for alternative methods of oxygenation and ventilation and potentially preventive of the need for tracheal intubation, such as non-invasive respiratory support techniques particularly valuable. In this context, the Emergency Department, located between the area outside the hospital and hospital ward and ICU, assumes the role of a crucial junction, due to the possibility of applying these techniques at a sufficiently early stage and being able to rapidly evaluate their effectiveness. This position paper describes the indications for the use of non-invasive respiratory support techniques in respiratory failure secondary to COVID-19-related pneumonia, formulated by the Non-invasive Ventilation Faculty of the Italian Society of Emergency Medicine (SIMEU) on the base of what is available in the literature and on the authors' direct experience. Rationale, literature, tips \& tricks, resources, risks and expected results, and patient interaction will be discussed for each one of the escalating non-invasive respiratory techniques: standard oxygen, HFNCO, CPAP, NIPPV, and awake self-repositioning. The final chapter describes our suggested approach to the failing patient.
\end{abstract}

Keywords COVID-19 $\cdot$ CPAP $\cdot$ HFNCO $\cdot$ NIPPV $\cdot$ Non-invasive respiratory support $\cdot$ NIV

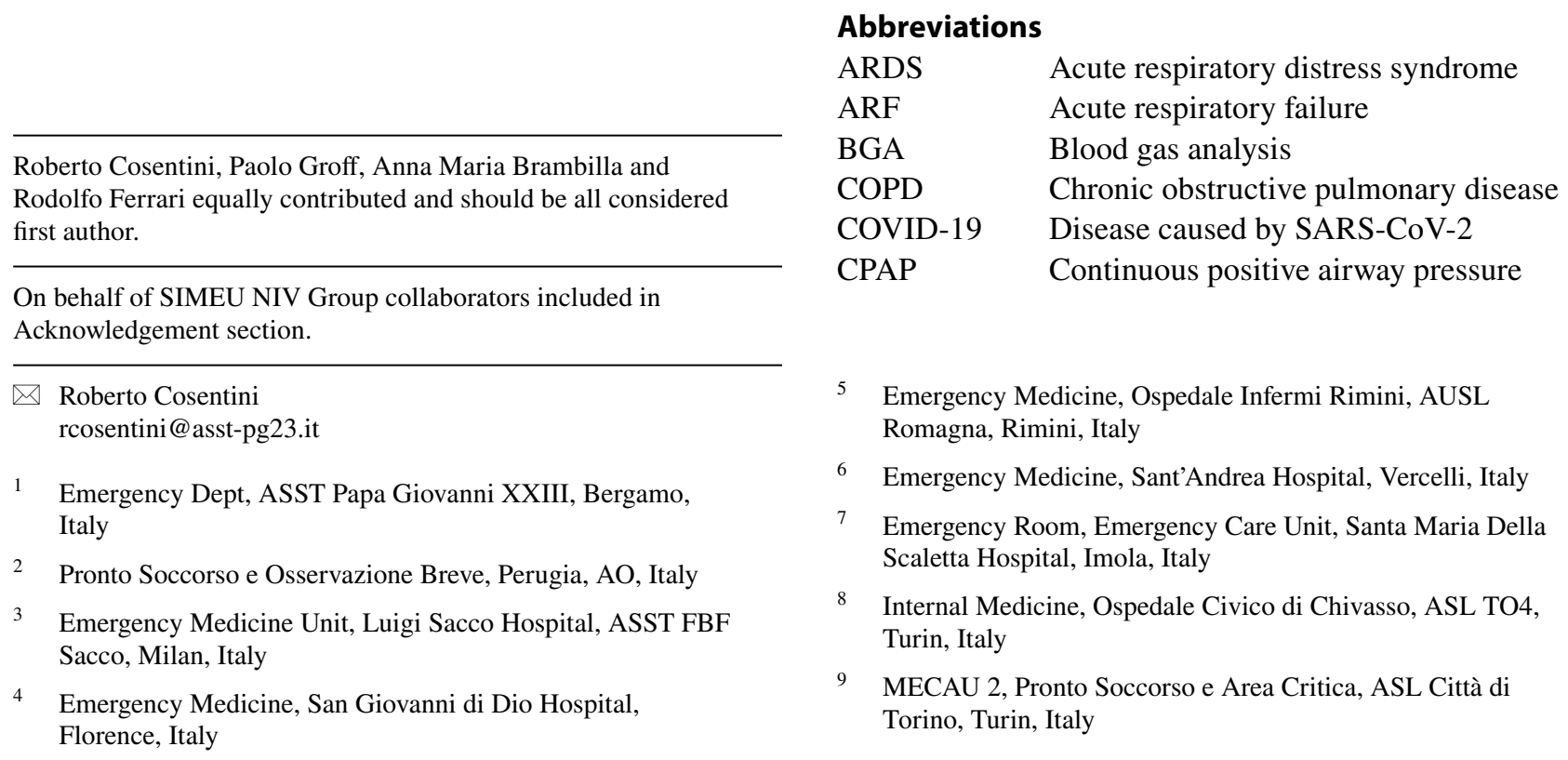




$\begin{array}{ll}\text { ETI } & \begin{array}{l}\text { Endo Tracheal intubation } \\ \text { FIO }\end{array} \\ \text { Fractional concentration of inspired } \\ \text { oxygen }\end{array}$

\section{Introduction}

In March 2020, after the SARS-CoV-2 infection spread from China to the rest of the world, the World Health Organization declared a pandemic [1]. The massive number of sick patients posed a unique challenge to every health system. The high frequency of respiratory involvement $[2,3]$ forced our hospitals to rapidly reorganize and redeploy doctors and nurses to acute care wards and adapt our protocols. To help our colleagues, we issued an early position paper on Non-invasive Oxygenation for COVID-19 patients at the beginning of the first wave [4, 5]. Since March 2020, several observational studies have been published involving thousands of COVID-19 patients treated for acute respiratory failure (ARF). It is time to give some suggestions based on this best available evidence, even though no randomized controlled trials (RCT) have been published to date.

\section{Methods}

We divided the topic into 8 chapters, 5 on different techniques of respiratory support and the last one focused on the failure of non-invasive support. Chapters are: 1. COVID19 Pathophysiology; 2. Indication to oxygen therapy; 3. Conventional oxygen therapy systems; 4 . The role of High Flow Nasal Cannulae Oxygenation (HFNCO); 5. Continuous Positive Airway Pressure (CPAP) efficacy and safety;
6. Non-invasive double level Positive Pressure Ventilation (NIPPV) efficacy and safety; 7. Awake self re-positioning; 8 . When non-invasive respiratory support fails. Each chapter has been developed by 4 experts in Non-invasive Ventilation (NIV) techniques; recommendations have been made according to Evidence-Based Medicine (best evidence + clinical experience + patient values) and revised by the NIV SIMEU Faculty group. Each technique (chapters 2-6) is structured according to the following draft:

(a) Why it may work (rationale)

(b) What is known (the literature)

(c) Our recommendation

(d) Our experience (tips \& tricks)

(e) Resources (human/instrumental)

(f) Risks and expected success

(g) What I say to my patient

\section{COVID-19 pathophysiology}

In evaluating the use of Non-invasive Respiratory Support (NRS) in ARF secondary to COVID-19-related pneumonia, it is necessary to make some preliminary considerations. The pathophysiology of this condition is quite different from that of the main indications of NIV [6]. COVID-19 pneumonia is characterized by an initial phase of prevalent interstitial and microvascular involvement, which subsequently leads to a condition of diffuse alveolar damage with the formation of hyaline membranes, edema and fibrotic deposition [7]. Therefore, it is possible to believe that, at least in the first phase, lung compliance is not significantly compromised and that hypoxemia depends on the loss of the physiological mechanism of hypoxic vasoconstriction secondary to a dysregulation of the microcirculation induced by inflammation and the formation of microthrombi $[8,9]$. It follows that the best treatment of this condition may be the progressive increase of oxygen support rather than the application of positive pressures, aimed at alveolar recruitment, which will be better reserved for the next phase of full-blown ARDS [10].

In this scenario, the role of NRS techniques, and NIV in particular, is controversial. The application of pressure support to a patient who breathes spontaneously can generate an excessive swing of transpulmonary pressure inducing a real risk of producing a patient-Self Induced Lung Injury (p-SILI) [11-14]. It should be noted that the concept of pSILI responds more to a theoretical assumption than to concrete experimental evidence and in particular this picture has never been directly observed in patients with COVID19-related pneumonia. On this basis it has been debated by distinguished authors, especially insofar as the decision to intubate a patient would depend on it [15-17]. Besides, NIV 
may delay intubation and worsening the patient's prognosis $[11,12]$. Finally, NIV can involve the risk of environmental dispersion of droplets, with a consequent risk of contagion for healthcare workers [18-21]. However, CPAP applies a single level of pressure during the entire respiratory cycle, reducing the risk of excessive transpulmonary pressure. Furthermore, CPAP can determine an increase in resistance in the small vessels of the non-dependent regions of the lung, favouring the redistribution of perfusion to newly recruited depending areas in patients who have lost the mechanism of hypoxic vasoconstriction [22] and may reduce the likelihood of generating high transpulmonary pressure and tidal volume compared to NIPPV, as explained in chapter 6 [23].

Key concepts

(a) COVID-19 pathophysiology is a continuum between an initial 'soft phase' with hypoxemia determined by deranged hypoxic vasoconstriction and a later 'heavy' phase with lung atelectasis resembling the classical ARDS

(b) Hence, each phase needs an individualized therapeutic approach in terms of oxygenation and positive pressure application

\section{Indications to oxygen therapy}

The Literature. The use of supplemental oxygen in adults with COVID-19 has not been studied.

The target of $\mathrm{SpO}_{2}$ in adults with COVID-19 is uncertain.

Oxygen therapy is recommended as the first-line therapy for treating COVID-19-induced hypoxemia by the World Health Organization and the Center for Disease Control and Prevention. [24, 25]

The current COVID-19 management guidelines by Surviving Sepsis Campaign suggest the use of supplemental oxygen if the $\mathrm{SpO}_{2}$ is $<92 \%$ and recommend its use once $\mathrm{SpO}_{2}$ is $<90 \%$ [26].

The current oxygen target saturation range (OTSR) for patients with COVID-19 recommended by the National Institutes of Health is 92-96\% [27].

In non-COVID-19 pneumonia outpatients, oxygen saturations less than $92 \%$ are known to be associated with major adverse events [28].

Our recommendation

Start with oxygen therapy when $\mathrm{SpO}_{2}<94 \%$, obtained by an arterial blood gas analysis (BGA).

Choose high $\mathrm{FiO}_{2}$ if $\mathrm{SpO}_{2}<90$ (e.g., non-rebreather mask $15 \mathrm{~L} / \mathrm{min}$ ).

Choose low $\mathrm{FiO}_{2}$ if $\mathrm{SpO}_{2}$ range is $90-93 \%$ (e.g., nasal cannula 3-6 L/min).

In patients with chronic pulmonary disease, start with oxygen therapy if $\mathrm{SpO}_{2}<90-92 \%$
OTSR is $\geq 94-98 \%$ (avoid hyper-oxygenation)

In patients with chronic pulmonary disease, OTSR is 90-92\%.

All the indications refer to " $\mathrm{SpO}_{2}$ " and not to " $\mathrm{PaO}_{2}$ "; to start oxygen therapy look at $\mathrm{SpO}_{2}$ and perform BGA: then repeat $\mathrm{BGA}$ at least daily and when patient worsens.

Caveats

1. These patients frequently show a marked respiratory alkalosis; this means that with the same $\mathrm{SpO}_{2}$ the $\mathrm{PaO}_{2}$ is lower. Perform a BGA before starting any treatment and at least once daily.

2. Mind hypercapnia or even a slight increase in $\mathrm{PaCO}_{2}$ despite an increasing/high respiratory rate (RR).

3. Mind patients with chronic mechanical load (COPD, obesity, kyphoscoliosis etc.) who are at risk of hypercapnia and fatigue.

\section{Conventional oxygen therapy systems}

\section{Nasal oxygen cannula}

The nasal cannulae are the most common initial step for oxygen treatment in patients with mild hypoxemia. They are simple to use and inexpensive; furthermore, nasal cannulae are considered relatively safe due to the minimal generated aerosol with a low risk of SARS-CoV-2 spreading. The air dispersion depends on flow. With $1 \mathrm{~L} / \mathrm{min}$, the measured distance using a high-fidelity mannequin was $30 \mathrm{~cm}$, and $40 \mathrm{~cm}$ with $5 \mathrm{~L} / \mathrm{min}$ (Fig. 1).

Main drawbacks are: 1 . the low maximal $\mathrm{FiO}_{2}$ provided that can reach up to $40 \% ; 2$. the need for humidification if oxygen flow is $>6 \mathrm{~L} / \mathrm{min} ; 3$. The actual variable $\mathrm{FiO}_{2}$ depends on the patient's inspiratory flow [28-30].

\section{Simple mask}

Flow rates with simple masks reach approximately 5-10 L/ min. As with nasal cannulae, $\mathrm{FiO}_{2}$ depends on the patient's inspiratory flow.

The increase of oxygen supplementation via simple mask is marginal when compared to nasal cannulae.

Air dispersion: the measured distance using a high-fidelity mannequin at $10 \mathrm{~L} / \mathrm{min}$ was $40 \mathrm{~cm}$ (Fig. 1) [28-30].

\section{Venturi mask}

$\mathrm{FiO}_{2}$ delivered by Venturi mask is more precise and ranges from 24 to $60 \%$ of oxygen. Typical pre-specified flow rates range between 2 and $15 \mathrm{~L} / \mathrm{min}$. 
Fig. 1 Exhaled air dispersion distance according to oxygen device
Exhaled air dispersion

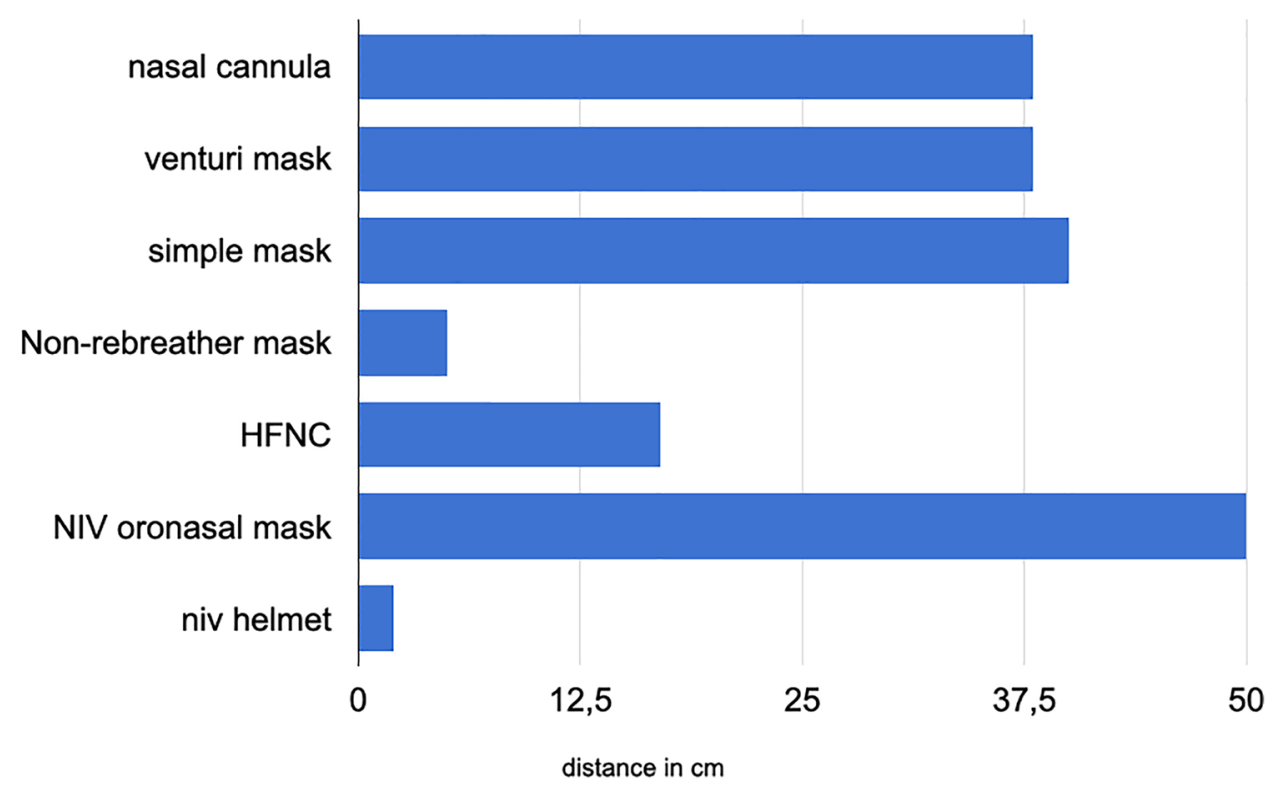

Air dispersion: the maximal measured distance using a high-fidelity mannequin varied from $33 \mathrm{~cm}$ at $\mathrm{FiO}_{2} 40 \%$, to $40 \mathrm{~cm}$ at $\mathrm{FiO}_{2} 24 \%$ [28-30].

\section{Non-rebreather mask}

The non-rebreather mask is a safer device to deliver oxygen to COVID-19 patients as the mask itself limits droplet dispersion. At $15 \mathrm{~L} / \mathrm{min}$, the $\mathrm{FiO}_{2}$ can reach $90 \%$.

Air dispersion: the maximal measured distance using a high-fidelity mannequin at $10 \mathrm{~L} / \mathrm{min}$ was less than $10 \mathrm{~cm}$ (Fig. 1). These data suggest that the non-rebreather mask provides the least aerosol dispersion [28-30].

\section{Use of surgical mask}

The use of a surgical mask to cover the nose and mouth over a nasal cannula or an oxygen mask has been suggested by several authorities including the World Health Organization.

In a recent study, the use of the surgical mask over or under an oxygen Hudson mask in 3 volunteers gave a negligible $\mathrm{FiO}_{2}$ difference measured at the lips [31].

OUR RECOMMENDATION. Choose the best oxygen system for your patients to obtain your target and the best comfort.

OUR EXPERIENCE. Patients generally increase their oxygen need gradually.

RESOURCES. Prepare in advance every type of device available for $\mathrm{O}_{2}$ administration; be ready to change from one to another rapidly.
RISKS. Always ask the patient to wear a surgical mask over the oxygen device.

EXPECTED SUCCESS. The vast majority of patients progress over days. A small percentage of patients worsens in a matter of hours from breathing air to need of intubation [32].

WHAT I SAY TO MY PATIENT. 'Your oxygenation is getting worse and this may damage your entire body. We need to start/change the device for oxygen administration'.

\section{The role of high flow nasal cannulae oxygenation}

\section{Why it may work}

As concerning the role of $\mathrm{HFNCO}$ in the non-intensive care setting, the available guidelines recommend its use before resorting to NIV [24, 33]. Actually, HFNCO can be the most suitable non-invasive support tool for treating COVID19-related respiratory failure, at least in its earliest stage, due to the possibility of delivering fixed and known $\mathrm{FiO}_{2}$, thanks to the creation of high flows of humidified and heated air-oxygen mixture. Besides, HFNCO achieves a PEEP of 2.5-5 $\mathrm{cm} \mathrm{H}_{2} \mathrm{O}$ and a continuous wash-out of $\mathrm{CO}_{2}$ of the dead space in the airways [34]. More recently, a Swedish monocentric experience conducted on a limited number of cases has shown how it is possible to improve the effectiveness of HFNCO simply by superimposing a conventional oxygen mask (without suppplemental O2) over the cannulas during treatment [35]. 


\section{The literature}

The analysis of the literature available on the subject allows us to detect studies that are very different from each other in terms of number and severity of patients enrolled, design, assessed outcomes.

In some experiences published immediately after the first pandemic peak, the use of HFNCO was conceived in the context of an oxygen escalation therapy in which the main outcome was to avoid resorting to the use of positive pressures, both by non-invasive and by conventional means, also with the aim of saving the use of ventilators in an Intensive Care Unit (ICU) resource constraint setting [36-38]. With this mode of use and selecting patients of moderate severity $\left(\mathrm{PaO}_{2} / \mathrm{FiO}_{2}>200 \mathrm{mmHg}\right)$ a success rate equal to two thirds of patients was described, while subsequent studies collected larger case series and more severe patients on average $\left(\mathrm{PaO}_{2} / \mathrm{FiO}_{2}<150 \mathrm{mmHg}\right)$, not excluding those with numerous co-morbidities or immunosuppression, again, in an operational context of severe ICU bed shortage [39-41]. With the limitations linked to a non-homogeneous definition of outcomes (escalation to positive pressures, intubation or intubation and death), these studies reported a lower percentage of success, around 50\% of treated patients. Interestingly, the authors observed a high percentage of deaths among patients who failed the method and often higher than that of patients who were intubated directly without carrying out therapy with HFNCO, corroborating observations that appeared in the pre-COVID-19 era on the fact that patients subjected to this method delayed the use of tracheal intubation worsening their outcome [42]. Particular importance was, therefore, reserved in these studies to the analysis of the risk factors of failure which were identified in the male sex, older age, increased respiratory rate and lower oxygenation upon entry. Of note, the prognostic performance of the ROX index (the ratio between $\mathrm{SpO}_{2} / \mathrm{FiO}_{2}$ and respiratory rate), already validated in the pre-COVID-19 era by Roca, was tested [43]. Even with different values and timing of measurements $(>3.7$ at $6 \mathrm{~h} ;>3$ at $2,6,12 \mathrm{~h}$ from the start of treatment; values increasing in the first 3 days from the start of treatment) it was invariably correlated with a favourable outcome. One study in particular [44], in addition to confirming the prognostic utility of the ROX index, showed that, among patients who failed, the timing of intubation (within $48 \mathrm{~h}$ or beyond $48 \mathrm{~h}$ ) did not influence intra-hospital mortality and other secondary outcomes. The Authors concluded that prolonged HFNCO trials were not clearly related to worse outcomes and that mortality was more likely to be attributed to a complex of factors related to the severity of the underlying disease.

An aspect that has often been pointed out in the discussion of the works cited so far is the fact that they are essentially cohort studies for the most part retrospective. They, therefore, do not have a control population and this allows judgments to be made on the effectiveness of HFNCO only in a very indirect way. Using a case-control analysis method, Demoule and co-workers retrospectively compared 137 COVID-19 patients treated with HFNCO for hypoxemic respiratory failure with 137 patients who received conventional oxygen therapy in ICU [45]; in the results, HFNCO was associated with a reduced proportion of patients requiring invasive mechanical ventilation at day 28 , while mortality at day 28 was similar between the two groups and this held true after adjusting for confounders.

The recent publication of the HENIVOT study by the Gemelli-ICU Study Group [46], has concretely contributed to the definition of the role of HFNCO and helmet-NIV in the treatment of hypoxemic ARF in patients admitted to the ICU for moderate to severe COVID-19 pneumonia, confirming the superiority of the latter in outcomes, such as the frequency of tracheal intubation at 28 days, correction of hypoxemia and dyspnea. However, it should be noted that while the level of monitoring obtainable in the ICU is difficult to generalize to other operational areas, the Same Authors Have previously reported an increase in endotracheal intubation in those patients who demonstrated an increase in trans-pulmonary pressure during helmet NIV [12]. In a large UK controlled randomized trial of 1272 patients, rapidly set up in the making of the pandemic, Perkins et al. compared CPAP and HFNCO to conventional oxygen treatment as to a combined primary outcome consisting of tracheal intubation or death at 30 days [47]. They found that CPAP, compared with conventional oxygen therapy, reduced the composite outcome, while there was no effect observed, compared to conventional oxygen therapy with the use of HFNCO. While some observations of a methodological nature, admitted by the authors themselves, lead to a cautious interpretation of these data, more generally, it must be considered that in particularly severe situations $\left(\mathrm{PaO}_{2} /\right.$ $\mathrm{FiO}_{2}<150$ ), i.e., when a lung damage corresponding to the ARDS type (high elastance, high recruitability) is conceivable, the use of positive pressure techniques may well achieve better results in terms of oxygenation. It remains to be investigated what the role of HFNCO may be in the patient with mild respiratory insufficiency (low elastance, low recruitability) in which this method could prevent the need for positive pressure techniques in the escalation of oxygen therapy. The COVID-HIGH international multicenter randomized controlled trial (COVID-HIGH trial, NCT04655638) that is completing patient enrollment as we write will certainly provide valid answers in this regard.

A final aspect to consider concerns the safety of healthcare workers with respect to the possible airborne transmission of the virus during treatment with HFNCO. In this regard, it should be noted that already at the time of the SARS and MERS pandemics [48, 49], data had been 
produced that showed that among the various devices that could be used HFNCO is one of those least correlated with the dispersion of potentially infected droplets. The use of a surgical mask placed on the patient's face during treatment significantly reduces this risk. It should also be said that among the studies cited so far, those that have dealt with this problem have reported a very low incidence of SARS-CoV-2 infection among health professionals during the study period and mostly not related to us of HFNCO.

OUR RECOMMENDATION. Considering the studies analyzed, the use of HFNCO may be effective in the treatment of moderate to severe respiratory failure secondary to COVID-19-related pneumonia, preventing the use of other support techniques, such as CPAP or NIPPV.

We recommend its use for 1 to $2 \mathrm{~h}$ in patients with $\mathrm{SpO}_{2}<92 \%$ or $\mathrm{PaO}_{2} / \mathrm{FiO}_{2} 200-300 \mathrm{mmHg}$ during treatment with a non-rebreathing mask at $15 \mathrm{~L} / \mathrm{min}$ for at least $15 \mathrm{~min}$, before sorting to CPAP in case of failure of the technique to correct these values.

We strongly recommend close clinical monitoring of the patient and check of gas exchange after $2 \mathrm{~h}$ of treatment in order not to delay the escalation of therapy in case of deterioration. The determination of a ROX index value $>4$ at this timepoint correlates with a better outcome of the technique.

From a practical point of view, we recommend choosing a cannula size appropriate to the size of the patient's nostrils; adjust the flow to $60 \mathrm{~L} / \mathrm{min}$ and titrate it down to patient comfort; adjust the temperature of the mixture to patient comfort starting from $31^{\circ} \mathrm{C}$; enrich the oxygen mixture by titrating it to the therapeutic target $\left(\mathrm{SpO}_{2}>92 \%\right)$.

We also recommend placing a surgical mask on the patient's face during treatment.

OUR EXPERIENCE. The patients who seem to benefit the most are those with hypoxemia and respiratory alkalosis during conventional oxygen therapy without marked dyspnoea or respiratory distress. The ability to compensate the patient-generated inspiratory flows with the high flows generated by the device allows to precisely titrate the $\mathrm{FiO}_{2}$ to the saturation target. Furthermore, HFNCO is particularly comfortable for the patient, even during maneuvers, such as awake pronation.

RESOURCES. One trained operator. One HFNCO device and its disposables. One non-invasive monitoring system.

RISKS. The greatest risk is to continue the treatment for too long without adequate monitoring, clinical and BGA improvement.

EXPECTED SUCCESS. HFNCO can be effective in up to two-thirds of patients with moderate respiratory failure if well selected.

WHAT I SAY TO MY PATIENT. 'Your oxygenation is getting worse due to the COVID-19-related pneumonia you suffer from. The simple oxygen mask we are using is no longer sufficient for this purpose. Now, we will use a device that, in addition to improving oxygenation, will make you feel very comfortable. In any case, we will continue to periodically check your values'.

\section{CPAP efficacy and safety}

CPAP systems are widely but heterogeneously used in the treatment of severe refractory hypoxemia that characterizes COVID-19, with a predominantly empirical approach in the Emergency Department.

\section{Why it may work}

Pathophysiologically, CPAP in COVID-19 can: a. Lead to increased resistance in the small vessels of non-dependent regions of the lung, favouring the redistribution of perfusion to newly recruited depending areas when the hypoxic vasoconstriction mechanism has been lost; $b$. Allow saving the inflamed lung parenchyma by the traumatizing phenomenon of recruitment and de-recruitment; c. Reduce the respiratory work and distress and avoid the reduction of the residual functional capacity; d. Improve the compliance of the thoracic-pulmonary system increasing the percentage of ventilated alveoli; e. improve the oxygenation even in refractory hypoxemia during conventional oxygen therapy with moderately preserved pulmonary compliance $[9,18$, 50]. f. Reduce the risk of excessive transpulmonary pressure.

CPAP may cause delayed intubation and the need for emergency airway management [51], and increase the risk of viral spread into the environment with a major rate of infection and contamination of health workers.

The use of CPAP, as well as that of NIPPV, in respiratory pandemics, has been reported in the past in quantitatively and qualitatively poor studies; the effectiveness of NIV is, therefore, too limited to allow for any kind of widespread recommendation and rather requires serious caution [6].

Nowadays, the relationship between the potential benefit in cases of mild to moderate hypoxaemic ARF, the amount of droplet dispersion, the risk of inadequacy, waste of resources, and time in applying invasive and intensive measures, are still debated.

The clinical and ventilatory picture of COVID-19 is halfway between pneumonia and ARDS [7, 9, 10, 52-56], thus representing a very high risk of CPAP failure, even if in expert hands in an intensive/semi-intensive environment.

\section{The literature}

Most of the available studies in the literature are the results of observational retrospective monocentric experiences, and only a couple of them are prospective. Consequently, main considerations derive from theoretical assumptions 
and there is still substantial uncertainty about the selection criteria, risk stratification, timing, defined indications, duration, and success or failure criteria for CPAP in COVID-19 [18, 57-77].

A meta-analysis on 3377 patients from 17 observational investigations treated with non-invasive respiratory support has been recently published All patients were treated outside the ICU, $80 \%$ with CPAP, and the rest with NIPPV [78]. Inhospital mortality was $36 \%$ (30-41\%). $26 \%$ (21-30\%) of the patients failed NRS and required intubation, with an intrahospital mortality rising to $45 \%$ (36-54\%).

More recently, an adaptive RCT has been published as an online preview (non-peer reviewed) by Perkins et Al. [47]. The Authors randomized 1271 patients with severe COVID19 pneumonia (mean $\mathrm{PaO}_{2} / \mathrm{FiO}_{2}=131-138 \mathrm{mmHg}$ ) into 3 groups, $380 \mathrm{CPAP}, 417 \mathrm{HFNCO}$, and 475 conventional oxygen therapy. Primary composite outcome (ETI or death) was significantly lower in the CPAP Group (36\%) vs conventional oxygen (44\%), mainly by a reduction of ETI (33\% vs $41 \%$, adjusted OR 0.66 (95\% CI $0.47-0.93$ ) rather than mortality ( 16.7 vs $19.2 \%$, OR 0.91 (95\% CI $0.59-1.39)$ ). If these data will be confirmed after the scientific review, the pendulum of efficacy will move significantly toward CPAP choice in severe COVID-19 pneumonia.

A pivotal issue is that of environmental safety and the risk of viral contamination $[19,79,80]$. Nowadays, the helmet seems the least dispersive interface [19, 21, 81-86]. Given the risk of airborne dispersion of droplets from devices with high oxygen flow, it is advisable to limit their use to isolated environments with negative pressure or to isolated and wellventilated areas. To significantly reduce droplet dispersion, a certified antiviral/antibacterial filter should be mounted in series between the oxygen source and the interface, and a second between the interface and the interchangeable PEEP valve on the exhalation port.

It seems rational to recommend the early use of CPAP in hypoxaemic ARF in a moderate phase of the clinical course, for hemodynamically stable patients, with preserved neurological status (Kelly-Matthay scale $=1$ ) [87], unscathed respiratory dynamics, $\mathrm{RR} \geq 25 \mathrm{bpm}$, with $\mathrm{SpO}_{2}<90 \%$ or $\mathrm{PaO}_{2}<60 \mathrm{mmHg}$ during standard oxygen with elevated $\mathrm{FiO}_{2}$ via Venturi or non-rebreathing mask or HFNCO sustained at $50 \mathrm{~L} / \mathrm{min}$. The choice of high CPAP values, between 7.5 and $12.5 \mathrm{~cm} \mathrm{H}_{2} \mathrm{O}$, and high $\mathrm{FiO}_{2}$ is recommended to achieve the OTSR of 94-98\% (69); the goal should be lower (90-92\%) in patients at risk of hypercapnia.

The use of CPAP, also in COVID-19, can be recommended, where monitoring is guaranteed with trained medical and nursing staff, and with rapid access to invasive ventilation without any delay in case of failure. CPAP can be safely and effectively delivered outside ICU in some dedicated Emergency Department settings, built as High Dependency Respiratory Units with appropriate staff and monitoring, along with ensuring cross-specialty collaboration.

Age, baseline $\mathrm{SpO}_{2}$, baseline $\mathrm{PaO}_{2} / \mathrm{FiO}_{2}$ ratio, and comorbidities can be considered as main outcome predictors for success or failure.

Response to CPAP cannot be expected to be rapid and any signs of deterioration should be monitored at the beginning and the following days. In the interval phases in which CPAP is temporarily suspended, the decrease in $\mathrm{SpO}_{2}$, an increase in RR, the appearance of respiratory distress with activation of the accessory muscles, and pump failure represent signs of treatment failure.

OUR RECOMMENDATION. Consider the use of CPAP in any case of severe hypoxemia unresponsive to conventional oxygen therapy. Place an antiviral and antibacterial filter both between the oxygen source and the patient and between the patient and the external environment. Minimize leakages.

OUR EXPERIENCE. Responders usually show quick improvement in $\mathrm{SpO}_{2}$ and $\mathrm{PaO}_{2} / \mathrm{FiO}_{2}$ and reduction in work of breathing (WOB); the gain overtime is usually initially limited and then slowly gradually progressive, as well as that of the RR and the respiratory pattern. Even failure is usually slowly gradual and progressive over time.

RESOURCES. Choose from different CPAP devices based on the specific range of PEEP, $\mathrm{FiO}_{2}$, and flows based on different patient targets. Choose the most comfortable interface based on the patient's preferences.

RISKS. Delay in ETI and invasive ventilation when needed and recommended, squandering of resources, interface drawbacks, aerosol generation, and droplet dispersion.

EXPECTED SUCCESS. Optimal adaptation to the interface, moderate hypoxemia (interpreted together with $\mathrm{PaO}_{2} /$ $\mathrm{FiO}_{2}$ ), intact neurological status, improved BGA and $\mathrm{RR}$ in the first hours, low physiological score, absence of relevant chronic comorbidities are predictors of success.

WHAT I SAY TO MY PATIENT. "Pneumonia caused by the virus creates a kind of barrier that makes your response to oxygen-therapy unsatisfactory. We can step up with treatment by adding continuous pressure via a different device and a different interface. The first phase is slightly uncomfortable, but you will see that you will soon adapt and we will do our best to help you tolerate it and to optimize your comfort".

\section{NIPPV efficacy and safety}

\section{Why it may work}

NIPPV is defined as intermittent positive pressure ventilation in two different alternating levels. 
Most of what has been said about CPAP in COVID-19 in terms of pathophysiology also applies to NIPPV.

NIPPV provides: a. The addition of pressure support to inspiration; $b$. The improvement of tidal volume reducing the work of breathing and respiratory distress; $c$. The achievement of a wider range of PEEP and $\mathrm{FiO}_{2}$ values; d. The stability of $\mathrm{FiO}_{2}$ for a wider range of minute ventilation; e. Less dispersion of droplets (especially via the helmet) [19, 30]; f. The graphical monitoring of ventilator parameters, flow and pressure waveforms; $g$. The humidification of the circuit.

Compared to CPAP, NIPPV is less simple, positive pressures are less stable with increasing risk of patient-ventilator asynchronies, of generating excessively and unmeasurable swings of the intrathoracic pressure, and excessive tidal volume and total ventilation which ended in p-SILI.

\section{The literature}

The vast majority of patients treated with NIPPV have been described in the literature in observational studies [37, 61, $63-65,70,71,75,78,88-92]$, accounting for more than 500 patients, a far lower number than CPAP patients described in the literature ( $>2.500)$, with only one RCT on helmet NIPPV vs HFNCO and not standard $\mathrm{O}_{2}$ in moderate-tosevere COVID-19 pneumonia $\left(\mathrm{PaO}_{2} / \mathrm{FiO}_{2} \leq 200 \mathrm{mmHg}\right)$ [45]. In this only RCT on NIPPV, the authors found no difference in the primary outcome of respiratory support-free days.

Patients with COVID-19 can develop both interstitial pneumonia and ARDS, which is associated with high mortality; in this scenario, the role of NIPPV is uncertain and still debated, both for efficacy and safety. There is no shared evidence (it is, in fact, even lower than CPAP) to recommend NIPPV in ARF and ARDS due to COVID-19, and the risk of delaying an appropriate invasive mechanical ventilation must always be considered first and foremost: a clear decision on ETI must be made before initiating NIV in any patient affected by COVID- 19 .

NIPPV should be early preferred to CPAP in case of initial signs of muscle exhaustion and a trend towards respiratory acidosis, with a low threshold in the inclusion of patients with do-not-intubate and comfort-measures-only orders for which NIPPV may be preferred as a palliative ceiling treatment.

$\mathrm{FiO}_{2}$ has to be set to achieve OTSR, PEEP should be high enough $\left(7.5-12 \mathrm{cmH}_{2} \mathrm{O}\right)$ to obtain adequate alveolar recruitment and oxygenation under conditions of disadvantageous compliance, inspiratory pressure to get towards a lower than normal tidal volume (4 to $6 \mathrm{ml} / \mathrm{kg}$ of ideal body weight), inspiratory trigger must be maintained with maximum sensitivity, inspiratory pressure rise time must balance rapid pressurization and leakages in both restrictive and obstructive scenarios $(0.15-0.25 \mathrm{~s})$, expiratory trigger cautiously at $30 \%$ of peak flow.

When choosing the helmet as the interface, instead of the oro-nasal or full-face mask [93], the possibility of noninvasive monitoring of tidal volume and minute ventilation is largely lost, and the setting of ventilator parameters requires particular caution and skills. $\mathrm{FiO}_{2}$ is set as usual according to OTSR, PEEP should be set higher than usual, inspiratory pressure support higher than with face masks, inspiratory trigger must be maintained maximally sensitive (carefully observing the appearance of autotriggering phenomena), quicker inspiratory pressure rise time, earlier expiratory trigger. The advantage of helmet NIPPV is safety, since it is a closed circuit with an interface with minimal leakage when compared to the mask [94].

OUR RECOMMENDATION. Consider the use of NIPPV for concomitant COPD, a trend to respiratory acidosis (before the onset of muscle exhaustion), or the need to reach a wider range of $\mathrm{FiO}_{2}, \mathrm{PEEP}$ and flows. Place an antiviral and antibacterial filter in both inspiratory and expiratory ways. Minimize leakages.

OUR EXPERIENCE. Responders usually show slowly gradual and progressive improvement in RR, respiratory pattern, $\mathrm{PaCO}_{2}$, and resting of respiratory muscles. Even failure is usually slowly progressive over time.

RESOURCES. Ventilators must ensure high performances, such as to optimize synchronization, proportionality and servo-control, and the fine setting of all parameters including inspiratory and expiratory triggers, rise-time and alarms. Choose the most comfortable interface based on the patient's preferences and its sustainability by the ventilator.

RISKS. Patient-ventilator asynchrony, p-SILI, delay in ETI and invasive ventilation when needed and recommended, squandering of resources, interface drawbacks, aerosol generation and droplets dispersion.

EXPECTED SUCCESS. Optimal adaptation to the interface, moderate hypoxemia (interpreted together with $\mathrm{PaO}_{2} / \mathrm{FiO}_{2}$ ) and hypercapnia (with no signs of muscle exhaustion), intact neurological status, improved BGA and respiratory pattern in the first hours, low physiological score, absence of relevant chronic comorbidities (COPD excluded) are predictors of success. Expect a high failure rate in the very old, very low $\mathrm{PaO}_{2} / \mathrm{FiO}_{2}$ ratio and comorbidities.

WHAT I SAY TO MY PATIENT. 'You are getting worse in both oxygenation and ventilation. We can intensify the treatment by adding some pressures that will actively support you in breathing. We will use different interfaces and devices that will follow you in your spontaneous breath. We will need your help to bring you maximum tolerance and comfort'. 


\section{Awake self re-positioning}

\section{Why it may work}

It has been postulated [10] that the main mechanism of hypoxemia in COVID-19 pneumonia is the loss of hypoxic vasoconstriction. This may lead to blood maldistribution and shunt effect by the perfusion side (increased perfusion of non-aerated alveoli). The other effect of pronation is alveolar recruitment of basal regions and reduced dorsal over-distension. This leads to ventilation/perfusion mismatch improvement of non-dependent areas. These actions are probably more involved in the late phase of COVID-19 disease when the lung parenchyma is heavily consolidated, and therefore, atelectasis is predominant.

In summary: a. Position changes might correct the blood maldistribution, thus improving ventilation/perfusion mismatch. b. Awake patients do it by themselves (selfrolling) when instructed to, as opposed to ETI pronation that requires many operators. c. Awake self-repositioning can be applied in every phase of the oxygen escalation and should be attempted at least before ETI.

\section{The literature}

To date, more than 300 patients treated with awake pronation with different $\mathrm{O}_{2}$ treatment, from nasal prongs to HFNCO or CPAP or NIPPV have been described in observational studies [95].

The only observational prospective study on the awake prone and lateral position was published by Retucci et al. [77] in 26 Respiratory Intensive Care Unit patients. After a median of $1 \mathrm{~h}$, failure to improve was observed in $25 \%$ and $40 \%$ of pronated and lateral decubitus patients, respectively. Twenty-seven $\%$ of patients were intubated.

The largest case series was reported by Coppo et Al. [62] who described 56 patients pronated for a mean of $3.5 \mathrm{~h} . \mathrm{PaO}_{2} / \mathrm{FiO}_{2}$ ratio was significantly improved $($ mean $+58 \%)$, and $32 \%$ were intubated.

The largest case series observed in the Emergency Department was reported by Caputo et al. [96]. After only 5 min of awake pronation in 50 patients, mean $\mathrm{SpO}_{2}$ rose from 84 to $94 \%$. Intubation was required in $14 \%$ of cases.

Longer pronation time (median $9.0 \mathrm{hs}$ ) was not superior to shorter time (median $3.4 \mathrm{hs}$ ) in a RCT performed by Rosen J et al. [97]

Overall, the heterogeneity of patients described in all the observational studies in terms of severity, oxygen treatment, and duration of pronation is well represented by the rate of intubation that ranged from 0 to $69 \%$ (mean $=28 \%$ ) [94]. Considering all studies, where at least 10 patients were described, awake pronation improved significantly the oxygenation $\left(\mathrm{PaO}_{2} / \mathrm{FiO}_{2}\right)$ in two-thirds of cases [94], without any benefit when longer than $12 \mathrm{~h}$.

OUR RECOMMENDATION. Start with positioning for $\geq 1 \mathrm{~h}$, ideally $3-6 \mathrm{~h}$. If clinical signs and oxygenation improve above 90-92\%, go on.

OUR EXPERIENCE. Responders show $\mathrm{SpO}_{2}$ improvement in the first $2 \mathrm{~h}$. The success rate is higher in diffuse interstitial patterns than consolidations. Explain to the patients that their lungs will possibly benefit from the maneuver; start with the more affected side for lateral decubitus. The response is usually rapid, within $1 \mathrm{~h}$. Sessions of at least 3-6 h.

RESOURCES. For patients on CPAP, one operator and a pillow are sufficient. Help the patient to turn with a pillow under the chest/ or hips/pelvis for pronation or behind the chest for the lateral decubitus. In patients in NIPPV, the manoeuvre may require more personnel and may be more troublesome.

RISKS. Tolerance may be an issue; some patient complains of a sensation of suffocation when pronated. Massive pulmonary embolism has been reported when intubated patients were first pronated.

EXPECTED SUCCESS. The overall reported success rate is moderate in terms of oxygenation improvement (2 out of 3), probably more with pronation than lateral decubitus.

WHAT I SAY TO MY PATIENT. Your oxygen is very low, and this is partly due to a maldistribution of blood into the lungs. To treat this, some studies suggest changing the position to improve blood distribution, either laterally or face down, as you do during sleep. If it works, we'll go on with this for 3-6 h a day for a few days.

\section{When non-invasive respiratory support fails}

The SARS-CoV-2 pandemic has posed a unique challenge to the world health system, not only in terms of diagnostics and treatment but also for hospital capacity and resources.

The key aim of the support is tissue oxygenation via sufficient oxygen saturation. If saturation cannot be achieved through non-invasive oxygenation, ETI is mandatory, although the patient has not received a do-not-intubate order, as in common clinical practice.

In these recommendations, we have proposed a step-bystep approach of non-invasive oxygenation to avoid both early intubation and the consequent ventilation-induced lung injury and delayed intubation for those who fail non-invasive oxygenation (Fig. 2, Non-invasive Respiratory Support escalation in COVID-19 pneumonia).

Then, the crucial decision is to define the criteria for noninvasive oxygenation failure. 


\section{Non invasive Respiratory Support escalation in COVID-19 pneumonia}

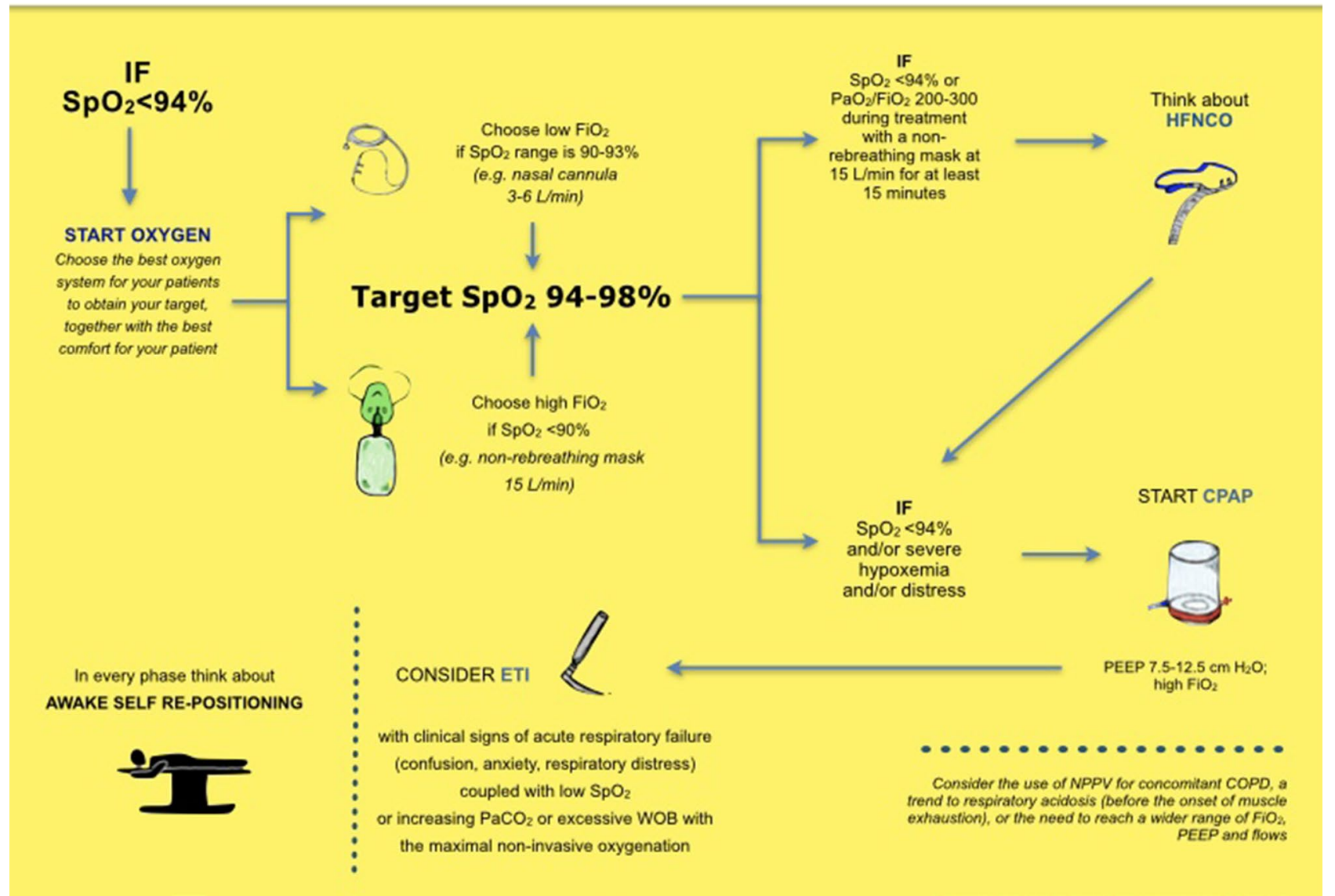

Fig. 2 Non-invasive respiratory support escalation in COVID19 pneumonia

As a rule, the further step to climb to ETI is when patients: a. failed to oxygenate; b. presented fatigue; $c$. increased their WOB.

We suggest clinicians to proceed to ETI whenever clinical deterioration ensues, such as confusion, anxiety or diaphoresis.

Let's define each-one of the three.

a. Hypoxemia.

Our patient failed to reach $\mathrm{SpO}_{2} \geq 92 \%$ with maximal NRS oxygen. In this case, we suggest using $\mathrm{SpO}_{2}$ instead of $\mathrm{PaO}_{2} / \mathrm{FiO}_{2}$ ratio because of its intrinsic limitations. In fact, $\mathrm{PaO}_{2} / \mathrm{FiO}_{2}$ depends on $\mathrm{FiO}_{2}$.

This means that: $\mathrm{a} \cdot \mathrm{PaO}_{2} / \mathrm{FiO}_{2}$ changes in the same patient according to $\mathrm{FiO}_{2}$ if there is a shunt effect [78-80], such as in COVID-19 pneumonia. Furthermore, $\mathrm{FiO}_{2}$ is reliable only if the patient is breathing room air or is invasively ventilated (no leaks).

b. $\mathrm{SpO}_{2}>90 \%$ is obtained whenever $\mathrm{PaO}_{2}>60 \mathrm{mmHg}$; this means that a wide range of $\mathrm{PaO}_{2}$, and therefore, $\mathrm{PaO}_{2} /$ $\mathrm{FiO}_{2}$ ratios may represent an acceptable $\mathrm{SpO}_{2}$. For instance, if a patient's BGA shows a $\mathrm{PaO}_{2} / \mathrm{FiO}_{2}$ ratio of $120 \mathrm{mmHg}$, while on CPAP with a $\mathrm{FiO}_{2}$ of $60 \%$, it means that $\mathrm{PaO}_{2}$ is 70 with a saturation well above $92 \%$. If the intubation algorithm considers a $\mathrm{PaO}_{2} / \mathrm{FiO}_{2}$ threshold below $150 \mathrm{mmHg}$, this patient should be intubated despite satisfactory oxygenation. If the patient is not in distress, the low $\mathrm{PaO}_{2} / \mathrm{FiO}_{2}$ means that the gas exchange is severely compromised, not that the patient is "hypoxemic' despite the treatment.

In conclusion, $\mathrm{PaO}_{2} / \mathrm{FiO}_{2}$ represents the severity of gas exchange impairment and is very useful to compare case series. However, it should not be the only parameter to consider for intubation.

Therefore, it seems reasonable to wait for intubation until the patient's arterial saturation drops below $92 \%$ for at least 30 min while on maximal non-invasive oxygenation and develops signs of clinical deterioration, such as confusion, anxiety, or diaphoresis, and increasing respiratory rate rather than relying solely on the $\mathrm{PaO}_{2} / \mathrm{FiO}_{2}$ ratio.

Another interesting clinical score to classify the severity of acute respiratory failure is the ROX index $\left(\mathrm{SpO}_{2} / \mathrm{FiO}_{2} /\right.$ $\mathrm{RR})$, formerly developed to predict intubation in patients treated with HFNCO [42]. In the original papers, the 
recourse to intubation was significantly higher in patients with an index $<4.88$. The ROX index may be attractive, because it combines the gas exchange impairment, expressed by $\mathrm{FiO}_{2}$ needed to obtain a certain $\mathrm{SpO}_{2}$, together with the clinical sign of RR.

b. Fatigue

Patients who develop fatigue with an increasing $\mathrm{PaCO}_{2}$ despite an increase of RR should be intubated. The intubation delay has been shown to lead to a worse prognosis [98-103].

The clinical picture of impending fatigue with $\mathrm{PaCO}_{2}$ increase is presumably connected to the evolution to the final phase of COVID-19 disease with the typical ARDS picture [32].

$c$. Increased work of breathing

Patients with ARF may present with hypoxemia associated with increased WOB and hypocarbia. It's been postulated that the increased intrapleural negative pressure and its consequent increased transpulmonary pressure may have deleterious effects on the lung, the so-called p-SILI. The increase of transpulmonary pressure may lead to further lung damage and increased permeability with interstitial thickening and further gas exchange derangement $[12,99$, 104, 105].

One major limitation is that WOB is an invasive measure via an oesophageal balloon, and therefore, it is not suitable for NRS. An interesting paper by Apigo et al. [106] measured non-invasively the WOB of consecutive patients with COVID-19 ARF treated with HFNCO. The WOB evaluation was performed clinically adding to the RR the use of accessory muscles (inspiratory via a. nasal flaring and b. sternocleidomastoid muscle; expiratory via c. abdominal muscles). The authors found that patients with increased WOB (WOB Index $>4$ with a predominant use of accessory muscles) were more frequently intubated than those with tachypnoea and a lower WOB $\leq 4$ ).

In patients treated with NIPPV, the exhaled tidal volume is related to intrapleural swings, and when expired tidal volume is higher than $6 \mathrm{~mL} / \mathrm{kg}$ the risk of p-SILI increased.

In summary, Avoidance of p-SILI must be balanced with ventilation-induced lung injury due to early intubation [105, 107]. It is wise to stick to the clinical ground beyond numbers, looking for the very first signs of clinical deterioration of confusion, anxiety, or diaphoresis.

This aspect underlines the fundamental role of clinical and instrumental monitoring of these patients, as in every critically ill population. In particular, the main focus should be addressed to the circulatory function, which allows adequate oxygen tissue delivery. Perfusion is best checked clinically with mental status, urine output, capillary refill, and skin perfusion (temperature and color: cold extremities and/or mottling are clear-cut signs of hypoperfusion). In parallel, heart function may be monitored non-invasively with point-of-care ultrasound, looking for inferior vena cava collapsibility, left ventricle contractility, and right ventricle performance by tricuspid annular plane systolic excursion, especially if patients are treated with positive pressure.

OUR RECOMMENDATION. Consider tracheal intubation in patients with clinical signs of acute respiratory failure (confusion, anxiety, respiratory distress) coupled with low $\mathrm{SpO}_{2}$ or increasing $\mathrm{PaCO}_{2}$ or excessive WOB with the maximal non-invasive oxygenation. Do not rely solely on numbers $\left(\mathrm{PaO}_{2} / \mathrm{FiO}_{2}\right.$ or other scores, such as ROX index).

OUR EXPERIENCE. Look for $\mathrm{PaO}_{2}$ and worsening clinical signs (confusion, anxiety, respiratory distress). Plan in advance; prepare a plan B; obtain a list of patients at risk and check it regularly.

RESOURCES. Time- and resource-consuming. If resources are limited (ICU beds, ventilators), consider a priority list according to the probability of success [108]. When intubate, wear personal protective equipment and remember that fewer people involved means less risk of contamination.

RISKS. To avoid the two clinical risks (too early vs too late intubation), refer to our recommendation, coupling numbers with clinical findings.

WHAT I SAY TO MY PATIENT. 'You're getting worse. The next step to treat you effectively is to sedate you to intubate your trachea and release your muscles and lungs'.

Acknowledgements \#Società Italiana di Medicina d'Emergenza e Urgenza (SIMEU) NIV Group Collaborators: Carlo Ancona, Pronto Soccorso AO San Giovanni Addolorata, Roma, Italy. Emanuela Bresciani, Pronto Soccorso e Medicina d'Urgenza Policlinico Umberto I, Roma, Italy. Irene Camporesi, Pronto Soccorso e Medicina d'urgenza, Rimini, Italy. Maria Carbone, Pronto Soccorso e Medicina d'Urgenza AORN S Anna e S Sebastiano, Caserta, Italy. Giuseppe Carpinteri, Medicina e Chirurgia d'Accettazione e d'Urgenza dell'Azienda Ospedaliero-Universitaria "Policlinico-Vittorio Emanuele" di Catania, Italy. Fabio Causin, Pronto Soccorso Oderzo, Italy. Ivan Curcio, ASL NA 1 Centro, Napoli, Italy. Ombretta Cutuli, MECAU Ospedale Policlinico San Martino, Genova, Italy. Giuseppe D’Antuono, Emergency Medicine, Ospedale Infermi Rimini, AUSL Romagna, Rimini, Italy. Antonella Dragonetti, MECAU 2, Pronto Soccorso e Area Critica, ASL Città di Torino. Elisa Fante, Pronto Soccorso e Medicina d'Urgenza Policlinico Umberto I, Roma, Italy. Giovanni Ferrari, Unita' di Terapia Semi-Intensiva Respiratoria, AO Ordine Mauriziano, Torino, Italy. Alessia Garramone, Pronto Soccorso AO San Carlo, Potenza, Italy. Alessandro Jachetti, Fondazione IRCCS Ca' Granda Policlinico, Milano, Italy. Cristina Magliocco, Pronto Soccorso, Sandro Pertini Hospital, Roma, Italy. Antonino Maffei, Medicina d'Urgenza e Pronto Soccorso dell'azienda ospedaliera "Moscati" di Avellino, Italy. Maria Luisa Maifreni, Pronto Soccorso ULSS Treviso, Italy. Mariangela Mattiazzo, Pronto Soccorso Ospedale Ca'Foncello, Treviso, Italy. Lucia Mazzoran, Pronto Soccorso e Medicina d'Urgenza Ospedale Santa Maria della Misericordia, Udine, Italy. Alice Morelli, Pronto Soccorso e Medicina d'Urgenza, Ospedale di Forlì, Italy. Giuseppina Petrelli, Pronto Soccorso e Medicina d'Urgenza, SO Madonna del Soccorso, San Benedetto del Tronto, Italy. Valentina Rosti, Pronto Soccorso e Medicina d'Urgenza, Emergency Department, ASST Papa Giovanni XXIII-Bergamo, Italy. Gabriele Valli, Pronto Soccorso AO San Giovanni Addolorata, Roma, Italy. 
Author contributions RC, PG, AMB, RF contributed to the idea of the paper and to the first draft of the manuscript. All authors commented on previous versions of the manuscript. All authors read and approved the final manuscript.

Funding None.

Data availability Not applicable.

Code availability Not applicable.

\section{Declarations}

Conflict of interest The authors declare that they have no conflict of interest.

Consent to participate Not applicable.

Consent for publication Not applicable.

\section{References}

1. WHO (2020) Director-General's opening remarks at the media briefing on COVID19- March. http://who.int/covid-19/infor mation

2. Murthy S, Gomersall CD, Fowler RA (2020) Care for critically ill patients with COVID-19. JAMA 323:1499-1500. https://doi. org/10.1001/jama.2020.3633.pmid:32159735

3. Grasselli G, Zangrillo A, Zanella A et al (2020) COVID-19 Lombardy ICU Network. Baseline characteristics and outcomes of 1591 patients infected with SARS-CoV-2 admitted to ICUs of the Lombardy region, Italy. JAMA 323(16):1574-1581. https:// doi.org/10.1001/jama.2020.5394

4. Groff P, Ferrari R, Cosentini R (2020) How to use High-Flow Nasal Cannula (HFNC) devices to provide oxygen to patients with CoViD-19 induced pneumonia. https://www.simeu.it/w/ articoli/leggiArticolo/4025/leggi

5. Ferrari R, Groff P, Cosentini R (2020). Continuous Positive Airway Pressure (CPAP) devices to provide oxygen to patients with CoViD-19 pneumonia. Part 2. https://www.simeu.it/w/articoli/ leggiArticolo/4026/leggi

6. Rochwerg B, Brochard L, Elliott MW et al (2017) Official ERS/ ATS clinical practice guidelines: noninvasive ventilation for acute respiratory failure. Eur Respir J 50:1602426

7. Gattinoni L, Coppola S, Cressoni M, Chiumello D (2020) COVID-19 does not lead to a "Typical" acute respiratory distress syndrome. Am J Respir Crit Care Med 201(10):1299-1300

8. Potus F, Mai V, Lebret M et al (2020) Novel insights on the pulmonary vascular consequences of COVID19. Am J Physiol Lung Cell Mol Physiol 319:L277-288

9. Dohnt S, Derom E, Van Braekel E et al (2020) The pathophysiology of "happy" hypoxemia in COVID-19. Respir Res 21:198

10. Gattinoni L, Chiumello D, Caironi P et al (2020) Covid-19 pneumonia: different respiratory treatments for different phenotypes? Intensive Care Med 14:1-4

11. Brochard L, Slutsky A, Pesenti A (2017) Mechanical ventilation to minimize progression of lung injury in acute respiratory failure. Am J Respir Crit Care Med 195(4):438-442

12. Grieco DL, Menga LS, Eleuteri D, Antonelli M (2019) Patient self-inflicted lung injury: implications for acute hypoxemic respiratory failure and ARDS patients on non-invasive support. Minerva Anesthesiol 85(9):1014-1023
13. Yoshida T, Grieco DL, Brochard L, Fujino Y (2019) Patients self-inflicted lung injury and positive end-expiratory pressure for safe spontaneous breathing. Curr Opin Crit Care 25(2):192-198

14. Yoshida T, Amato MBP, Kavanagh BP, Fujino Y (2019) Impact of spontaneous breathing during mechanical ventilation in acute respiratory distress syndrome. Curr Opin Crit Care 25(2):192-198

15. Tobin MJ, Laghi F, Jubran A (2020) Caution about early intubation and mechanical ventilation in COVID-19. Ann Intensive Care 10:78. https://doi.org/10.1186/s13613-020-00692-6

16. Tobin MJ, Laghi F, Jubran A (2020) P-SILI is not justification for intubation of COVID-19 patients. Ann Intensive Care 10:105. https://doi.org/10.1186/s13613-020-00724-1

17. Tobin MJ, Jubran A, Laghi F (2021) Noninvasive strategies in COVID-19: epistemology, randomized trials, guidelines, physiology. Eur Respir J 57:2004247. https://doi.org/10.1183/13993003. 04247-2020

18. Longhini F, Bruni A, Garofalo E et al (2020) Helmet continuous positive airway pressure and prone positioning: a proposal for an early management of COVID19 patients. Pulmunology 26(4):186-191

19. Hui DS, Chow BK, Lo T, Ng SS, Ko FW, Gin T, Chan MTV (2015) Exhaled air dispersion during noninvasive ventilation via helmets and a total facemask. Chest 147(5):1336-1343

20. Lucchini A, Giani M, Isgro S (2020) The "helmet bundle: in COVID-19 patients undergoing non invasive ventilation. Intensive Crit Care Nurs. https://doi.org/10.1016/j.iccn.2020.102859

21. Cabrini L, Landoni G, Zangrillo A (2020) Minimise nosocomial spread of 2019-nCoV when treating acute respiratory failure. Lancet 395:685

22. Cabrini L, Landoni G, Oriani A (2015) Noninvasive ventilation and survival in acute care settings: a comprehensive systematic review and meta-analysis of randomized controlled trials. Crit Care Med 43:880-888

23. Carteaux G, Millan-Guilarte T, De Prost N et al (2016) Failure of noninvasive ventilation for de novo acute hypoxemic respiratory failure: role of tidal volume. Crit Care Med 44:282-290

24. WHO (2020) Clinical management of severe acute respiratory infection when Novel coronavirus (2019-nCoV) infection is suspected: Interim Guidance. WHO/nCoV/Clinical/2020.3 January 28

25. CDC (2020) Interim infection prevention and control recommendations for patients with suspected or confirmed coronavirus disease 2019 (COVID-19) in Healthcare Settings. https://www.cdc. gov/coronavirus/2019-ncov/healthcare-facilities/dialysis.html

26. Alhazzani W, Møller MH, Arabi YM et al (2020) Surviving Sepsis Campaign: guidelines on the management of critically ill adults with Coronavirus Disease 2019 (COVID-19). Intensive Care Med 46:854. https://doi.org/10.1007/s00134-020-06022-5

27. Majumdar SR, Eurich DT, Gamble J-M, Senthilselvan A, Marrie TJ (2011) Oxygen saturations less than $92 \%$ are associated with major adverse events in outpatients with pneumonia: a population-based cohort study. Clin Infect Dis 52(3):325-331

28. Jiang B, Wei B (2020) Oxygen therapy strategies and techniques to treat hypoxia in COVID-19 patients. Eur Rev Med Pharmacol Sci 24:10239-10246

29. Whittle JS, Sacchetti IP, Atwood C, Rosenberg MS (2020) Respiratory support for adult patients with COVID-19. JACEP Open 1:95-101

30. Hui DS, Chan MT, Chow B (2014) Aerosol dispersion during various respiratory therapies: a risk assessment model of nosocomial infection to health care workers. Hong Kong Med J 20(suppl 4):9-13

31. Binks AC, Parkinson SM, Sabbouh V (2020) Oxygen: under or over a surgical facemask for COVID-19 patients? Anaesthesia. https://doi.org/10.1111/anae.15166 
32. Camporota L, Vasques F, Sanderson B, Barrett NA, Gattinoni L (2020) Identification of pathophysiological patterns for triage and respiratory support in COVID-19. Lancet Respir Med 8(8):752-754. https://doi.org/10.1016/S2213-2600(20)30279-4

33. National Institute of Health (NIH) (2020) Coronavirus disease 2019 (Covid-19). Treatment Guidelines. https://www.covid19tre atmentguidelines.nih.gov/

34. Schwabbauer N, Berg B, Blumenstock G et al (2014) Nasal High flow oxygen therapy in patients with hypoxic respiratory failure: effect on functional and subjective respiratory parameters compared to conventional oxygen therapy and non-invasive ventilation (NIV). BMC Anesthesiol 14:66

35. Dogani B, Manson F, Resman F et al (2021) The application of an oxygen mask, without supplemental oxygen, improved oxygenation in patients with severe COVID-19 already treated with high-flow nasal cannula. Crit Care 25(1):319

36. Wang K, Wei Z, Ji L et al (2020) The experience of high-flow nasal cannula in hospitalized patients with 209 novel coronavirus-infected pneumonia in two hospitals of Chongqing, China. Ann Intensive Care 10:37

37. Vianello A, Arcaro G, Molena B et al (2020) High flow nasal cannula oxygen therapy to treat patients with hypoxemic acute respiratory failure consequent to SARS-CoV-2 infection. Thorax 75(11):998-1000

38. Patel M, Gangemi A, Marron R et al (2020) Retrospective analysis of high flow nasal therapy in Covid-19-related moderate-tosevere hypoxaemic failure. BMJ Open Respir Res 7(1):e000650

39. Hu M, Zhou Q, Zheng R et al (2020) Application of high-flow nasal cannula in hypoxemic patients with COVID-19: a retrospective cohort study. BMC Pulm Med 20:324. https://doi.org/ 10.1186/s12890-020-01354-w

40. Calligaro GL, Lalla U, Audley G et al. The utility of high-flow nasal oxygen for severe COVID-19 pneumonia in a resource-constrained setting: a multicenter prospective observational study. EClinicalMedicine 2020; 28:100570

41. Xia J, Yi Z, Ni L et al (2020) High-flow nasal oxygen in Coronavirus disease, 2019 patients with acute hypoxemic respiratory failure: a multicenter, retrospective cohort study. Crit Care Med 48:e1079

42. Kang BJ, Koh Y, Lim CM et al (2015) Failure of high-flow nasal cannula therapy may delay intubation and increase mortality. Intensive Care Med 41(4):623-632

43. Roca O, Caralt B, Messika J et al (2019) An index combining respiratory rate and oxygenation to predict outcome of nasal Highflow therapy. Am J Respir Crit Care med 199(11):1368-1376

44. Chandel A, Patolia S, Brown W et al (2020) High-flow nasal cannula in COVID-19: outcomes of application and examination of the ROX index to predict success. Respir Care. https://doi.org/ 10.4187/respcare.08631

45. Demoule A, Vieillard Baron A, Darmon M et al (2020) Highflow nasal cannula in critically ill patients with severe COVID19. Am J Respir Crit Care Med 202:1039-1042

46. Grieco DL, Menga LS, Cesarano M et al (2021) Effect of Helmet noninvasive ventilation vs high-flow nasal oxygen on days free of respiratory support in patients with COVID-19 and moderate to severe hypoxemic respiratory failure. JAMA 325(17):1731-1743

47. Perkins GD, Ji C, Connolly BA et al (2021) An adaptive randomized controlled trial of non-invasive respiratory strategies in acute respiratory failure patients with COVID-19. medRxiv. https://doi.org/10.1101/2021.08.02.21261379

48. Raboud J, Shigayeva A, McGeer A et al (2020) Risk factors for SARS transmission from patients requiring intubation: a multicenter investigation in Toronto, Canada. PLoS ONE 5(5):e10717

49. Tran K, Cimon K, Severn M et al (2012) Aerosol generating procedures and risk of transmission of acute respiratory infections to healthcare workers: a systematic review. PLoS ONE 7(4):e35797
50. L'Her E, Deye N, Lellouche F et al (2005) Physiologic effects of noninvasive ventilation during acute lung injury. Am J Respir Crit Care Med 172:1112-1118. https://doi.org/10.1164/rccm. 200402-226OC

51. Robba C, Battaglini D, Ball L et al (2020) Distinct phenotypes require distinct respiratory management strategies in severe COVID-19. Respir Physiol Neurobiol 279:103455

52. Antonelli M, Conti G, Esquinas A et al (2007) A multiple-center survey on the use in clinical practice of noninvasive ventilation as a first-line intervention for acute respiratory distress syndrome. Crit Care Med 35:18-25. https://doi.org/10.1097/01.CCM.00002 51821.44259.F3

53. Brambilla AM, Aliberti S, Prina E et al (2014) Helmet CPAP vs. oxygen therapy in severe hypoxemic respiratory failure due to pneumonia. Intensive Care Med 40:942-949. https://doi.org/ 10.1007/s00134-014-3325-5

54. Cosentini R, Brambilla AM, Aliberti S et al (2010) Helmet continuous positive airway pressure vs oxygen therapy to improve oxygenation in community-acquired pneumonia: a randomized, controlled trial. Chest 138(1):114-120. https://doi.org/10.1378/ chest.09-2290

55. Gattinoni L, Chiumello D, Rossi S (2020) COVID-19 pneumonia: ARDS or not? Crit Care 24:154. https://doi.org/10.1186/ s13054-020-02880-Z

56. $\mathrm{Li} \mathrm{X}, \mathrm{Ma} X$ (2020) Acute respiratory failure in COVID-19: is it "typical" ARDS? Crit Care 24:198. https://doi.org/10.1186/ s13054-020-02911-9

57. Aliberti S, Radovanovic D, Billi F et al (2020) Helmet CPAP treatment in patients with COVID-19 pneumonia: a multicentre cohort study. Eur Respir J 56:2001935. https://doi.org/10.1183/ 13993003.01935-2020

58. Alviset S, Riller Q, Aboab J et al (2020) Continuous positive airway pressure (CPAP) face-mask ventilation is an easy and cheap option to manage a massive influx of patients presenting acute respiratory failure during the SARS-CoV-2 outbreak: a retrospective cohort study. PLoS ONE 15(10):e0240645

59. Arina P, Baso B, Moro V et al (2020) Discriminating between CPAP success and failure in COVID-19 patients with severe respiratory failure. Intensive Care Med 16:1-3. https://doi.org/10. 1007/s00134-020-06304-y

60. Brusasco C, Corradi F, Di Domenico A et al (2020) Continuous positive airway pressure in Covid-19 patients with moderate-tosevere respiratory failure. Eur Respir J. https://doi.org/10.1183/ 13993003.02524-2020

61. Burns GP, Lane ND, Tedd HM et al (2020) Improved survival following ward-based non-invasive pressure support for severe hypoxia in a cohort of frail patients with Covid-19: retrospective analysis from a UK teaching hospital. BMJ Open Respir Res 7(1):e000621

62. Coppo A, Bellani G, Winterton D et al (2020) Feasibility and physiological effects of prone positioning in non-intubated patients with acute respiratory failure due to COVID-19 (PRON-COVID): a prospective cohort study. Lancet Respir Med 8(8):765-774

63. Di Domenico SL, Coen D, Bergamaschi M, et al (2020) Clinical characteristics and respiratory support of 310 Covid-19 patients, diagnosed at the emergency room: a single-center retrospective study. pp $1-10$

64. Duca A, Memaj I, Zanardi F et al (2020) Severity of respiratory failure and outcome of patients needing a ventilatory support in the Emergency Department during Italian novel coronavirus SARS-CoV2 outbreak: preliminary data on the role of helmet CPAP and non-invasive positive pressure ventilation. EClinicalMedicine 24:100419

65. Franco C, Facciolongo N, Tonelli R et al (2020) Feasibility and clinical impact of out-of-ICU non-invasive respiratory support 
in patients with COVID-19 related pneumonia. Eur Respir J 56(5):2002130

66. Hallifax RJ, Porter BML, Elder PJD et al (2020) Successful awake proning is associated with improved clinical outcomes in patients with COVID-19: single-centre high-dependency unit experience. BMJ Open Respir Res 7(1):e000678

67. Long B, Lyang SY, Hicks C, Gottlieb M (2020) Just the facts: what are the roles of oxygen escalation and noninvasive ventilation in Covid-19? CJEM. https://doi.org/10.1017/cem.2020. 396

68. Dessap MA (2019) Frugal innovation for critical care. Intensive Care Med 45:252-254. https://doi.org/10.1007/ s00134-018-5391-6

69. Mukhtar A, Lofty A, Hasanin A et al (2020) Outcome of noninvasive ventilation in Covid-19 critically ill patients: a retrospective observational study. Anaesth Crit Care Pain Med 39:579-580

70. Nightingale R, Nwosu N, Kutubudin F et al (2020) Is continuous positive airway pressure (CPAP) a new standard of care for type 1 respiratory failure in Covid-19 patients? A retrospective observational study of a dedicated Covid-19 CPAP service. BMJ Open Respir Res 7(1):e000639

71. Novelli L, Raimondi F, Ghirardi A et al (2020) At the peak of Covid-19 age and disease severity but not comorbidities are predictors of mortality. Covid-19 burden in Bergamo, Italy. Panminerva Med. https://doi.org/10.23736/S0031-0808.20.04063-X

72. Oranger M, Gonzalez-Bermejo J, Dacosta-Noble F et al (2020) Continuous positive airway pressure to avoid intubation in SARS-CoV-2 pneumonia: a two-period retrospective case-control study. Eur Respir J 56:2001692

73. Pagano A, Porta G, Bosso G et al (2020) Non-invasive CPAP in mild and moderate ARDS secondary to SARS-CoV-2. Respir Physiol Neurobiol 280:103489. https://doi.org/10.1016/j.resp. 2020.103489

74. Pimentel MAF, Redfern OC, Hatch R et al (2020) Trajectories of vital signs in patients with Covid-19. Resuscitation 156:99-106

75. Privitera D, Angaroni L, Capsoni N et al (2020) Flowchart for non-invasive ventilation support in COVID-19 patients from a northern Italy Emergency Department. Intern Emerg Med 15(5):767-771

76. Radovanovic D, Rizzi M, Pini S et al (2020) Helmet CPAP to treat acute hypoxemic respiratory failure in patients with Covid19: a management strategy proposal. J Clin Med 9:1191

77. Retucci M, Aliberti S, Ceruti C et al (2020) Prone and lateral positioning in spontaneously breathing patients with COVID19 pneumonia undergoing noninvasive helmet CPAP treatment. Chest 158(6):2431-2435. https://doi.org/10.1016/j.chest.2020. 07.006

78. Cammarota G, Esposito T, Azzolina D, Cosentini R, Menzella F, Aliberti S, Coppadoro A, Bellani G, Foti G, Grasselli G, Cecconi M, Pesenti A, Vitacca M, Lawton T, Ranieri VM, Di Domenico SL, Resta O, Gidaro A, Potalivo A, Nardi G, Brusasco C, Tesoro S, Navalesi P, Vaschetto R, De Robertis E (2021) Noninvasive respiratory support outside the intensive care unit for acute respiratory failure related to coronavirus-19 disease: a systematic review and meta-analysis. Crit Care 25(1):268. https://doi.org/ 10.1186/s13054-021-03697-0

79. Ahn JY, An S, Sohn Y et al (2020) Environmental contamination in the isolation rooms of COVID-19 patients with severe pneumonia requiring mechanical ventilation or high-flow oxygen therapy. J Hosp Infect 106:570-576. https://doi.org/10.1016/j. jhin.2020.08.014

80. Crimi C, Noto A, Cortegiani A et al (2020) Noninvasive respiratory support in acute hypoxemic respiratory failure associated with COVID-19 and other viral infections. Minerva Anestesiol. https://doi.org/10.23736/S0375-9393.20.14785-0
81. Garcia-Castrillo L, Petrino R, Leach R et al (2020) European Society For Emergency Medicine position paper on emergency medical systems' response to COVID-19. Eur J Emerg Med 27:174-177. https://doi.org/10.1097/MEJ.0000000000000701

82. Heinzerling A, Stuckey MJ, Scheuer T et al (2020) Transmission of COVID-19 to health care personnel during exposures to a hospitalized patient - Solano County, California. MMWR Morb Mortal Wkly Rep 69(15):472-476. https://doi.org/10.15585/ mmwr.mm6915e5

83. Hui DS, Chow BK, Lo T et al (2019) Exhaled air dispersion during high-flow nasal cannula therapy versus CPAP via different masks. Eur Respir J 53:1802339

84. Leonard S, Atwood CW Jr, Walsh BK et al (2020) Preliminary findings of control of dispersion of aerosols and droplets during high velocity nasal insufflation therapy using a simple surgical mask: implications for high flow nasal cannula. Chest. https:// doi.org/10.1016/j.chest.2020.03.043

85. Schünemann HJ, Khabsa J, Solo K et al (2020) Ventilation techniques and risk for transmission of coronavirus disease, including COVID-19: a living systematic review of multiple streams of evidence. Ann Intern Med 173:204-216. https://doi.org/10.7326/ M20-2306

86. Whittle JS, Pavlov I, Sacchetti A et al (2020) Respiratory support for adult patients with COVID-19. J Am Coll Emerg Phys Open 1(2):95-101

87. Kelly BJ, Matthay MA (1993) Prevalence and severity of neurologic dysfunction in critically ill patients. Influence on need for continued mechanical ventilation. Chest 104:1818-1824. https:// doi.org/10.1378/chest.104.6.1818

88. Bouadma L, Lescure FX, Lucet JC et al (2020) Severe SARSCoV-2 infections: practical considerations and management strategy for intensivists. Intensive Care Med 46:579-582. https://doi. org/10.1007/s00134-020-05967-x

89. Ding L, Wang L, Ma W, He H (2020) Efficacy and safety of early prone positioning combined with HFNC or NIV in moderate to severe ARDS: a multi-center prospective cohort study. Crit Care 24:28. https://doi.org/10.1186/s13054-020-2738-5

90. Raoof S, Nava S, Carpati C, Hill NS (2020) High-flow, noninvasive ventilation and awake (nonintubation) proning in patients with coronavirus disease 2019 with respiratory failure. Chest 158:1992-2002. https://doi.org/10.1016/j.chest.2020.07.013

91. Suardi LR, Pallotto C, Esperti S et al (2020) Risk factors for noninvasive/invasive ventilatory support in patients with COVID19 pneumonia: a retrospective study within a multidisciplinary approach. Int J Infect Dis 100:258-263. https://doi.org/10.1016/j. ijid.2020.09.012

92. Groff P, Ferrari R (2021) Non-invasive respiratory support in the treatment of acute hypoxemic respiratory failure secondary to CoViD-19 related pneumonia. Eur J Intern Med 86:17-21. https://doi.org/10.1016/j.ejim.2021.02.015

93. Patel BK, Wolfe KS, Pohlman AS et al (2016) Effect of noninvasive ventilation delivered by helmet vs face mask on the rate of endotracheal intubation in patients with acute respiratory distress syndrome: a randomized clinical trial. JAMA 315(22):24352441. https://doi.org/10.1001/jama.2016.6338

94. Ferioli M, Cisternino C, Leo V, Pisani L, Palange P, Nava S (2020) Protecting healthcare workers from SARS-CoV-2 infection: practical indications. Eur Respir Rev 29(155):200068

95. Weatherald J, Solverson K, Zuege DJ, Loroff N, Fiest KM, Parhar KKS (2021) Awake prone positioning for COVID-19 hypoxemic respiratory failure: a rapid review. J Crit Care 61:63-70. https:// doi.org/10.1016/j.jcrc.2020.08.018

96. Caputo ND, Strayer RJ, Levitan R (2020) Early self-proning in awake, non-intubated patients in the emergency department: a single ED's experience during the COVID-19 pandemic. Acad Emerg Med 27(5):375-378. https://doi.org/10.1111/acem.13994 
97. Rosén J, von Oelreich E, Fors D, Jonsson Fagerlund M, Taxbro K, Skorup P, Eby L, Campoccia Jalde F, Johansson N, Bergström G, Frykholm P, PROFLO Study Group (2021) Awake prone positioning in patients with hypoxemic respiratory failure due to COVID-19: the PROFLO multicenter randomized clinical trial. Crit Care 25(1):209. https://doi.org/10.1186/ s13054-021-03602-9

98. Aboab J, Louis B, Jonson B, Brochard L (2006) Relation between $\mathrm{PaO} 2 / \mathrm{FIO} 2$ ratio and FIO2: a mathematical description. Intensive Care Med 32:1494-1497

99. Cabrini L, Ghislanzoni L, Severgnini P, Landoni G, Baiardo Redaelli M, Franchi F, Romagnoli S (2020) Early versus late tracheal intubation in COVID-19 patients: a pro-con debate also considering heart-lung interactions. Minerva Cardioangiol. https://doi.org/10.23736/S0026-4725.20.05356-6

100. Phua J, Weng L, Ling L et al (2020) Intensive care management of coronavirus disease 2019 (COVID-19): challenges and recommendations. Lancet Respir Med. https://doi.org/10.1016/ S2213-2600(20)30161-2

101. Mosier JM, Sakles JC, Whitmore SP et al (2015) Failed noninvasive positive-pressure ventilation is associated with an increased risk of intubation-related complications. Ann Intensive Care 5:4. https://doi.org/10.1186/s13613-015-0044-1

102. Yao W, Wang T, Jiang B, Gao F, Wang L, Zheng H (2020) Emergency tracheal intubation in 202 patients with COVID-19 in Wuhan, China: lessons learnt and international expert recommendations. Br J Anaesth. https://doi.org/10.1016/j.bja.2020.03. 026
103. Kangelaris KN, Ware LB, Wang CY et al (2016) Timing of intubation and clinical outcomes in adults with acute respiratory distress syndrome. Crit Care Med 44(1):120-129

104. Gattinoni L, Marini JJ, Busana M, Chiumello D, Camporota L (2020) Spontaneous breathing, transpulmonary pressure and mathematical trickery. Ann Intensive Care 10(1):88. https://doi. org/10.1186/s13613-020-00708-1

105. Tobin MJ, Laghi F, Jubran A (2020) P-SILI is not justification for intubation of COVID-19 patients. Ann Intensive Care 10(1):105. https://doi.org/10.1186/s13613-020-00724-1.PMID:32748116; PMCID:PMC7397710

106. Apigo M, Schechtman J, Dhliwayo N (2020) Development of a work of breathing scale and monitoring need of intubation in COVID-19 pneumonia. Crit Care 24:477. https://doi.org/10. 1186/s13054-020-03176-y

107. Spinelli E, Mauri T (2019) Lung and diaphragm protection during non-invasive respiratory support. Am J Respir Crit Care Med. https://doi.org/10.1164/rccm.201911-2240LE

108. Daugherty Biddison EL, Faden REL, Howard S, Gwon HS et al (2019) Too many patients. A framework to guide statewide allocation of scarce mechanical ventilation during disasters. Chest 155(4):848-854

Publisher's Note Springer Nature remains neutral with regard to jurisdictional claims in published maps and institutional affiliations. 